\title{
Bilevel positive airway pressure in tracheobronchomalacia
}

\author{
Nambron Prathyush Pradeep, ${ }^{1}$ Irfan Ismail Ayub (1) , ${ }^{2}$ Madhavan Krishnaswamy, ${ }^{1}$ \\ Gokulakrishnan Periakaruppan ${ }^{3}$
}

${ }^{1}$ Department of Internal Medicine, Sri Ramachandra Medical College and Research Institute, Chennai, Tamil Nadu, India

${ }^{2}$ Department of Pulmonary Medicine, Sri Ramachandra Medical College and Research Institute, Chennai, Tamil Nadu, India

${ }^{3}$ Department of Radiology, Sri Ramachandra Medical College and Research Institute, Chennai, Tamil Nadu, India

Correspondence to

Dr Irfan Ismail Ayub:

iia@rediffmail.com

Accepted 7 October 2021
Check for updates

(C) BMJ Publishing Group Limited 2021. No commercial re-use. See rights and permissions. Published by BMJ.

To cite: Pradeep NP, Ayub II, Krishnaswamy $\mathrm{M}$, et al. BMJ Case Rep 2021:14:e246331. doi:10.1136/bcr-2021

246331

\section{DESCRIPTION}

A 70-year-old man, with diabetes mellitus and systemic hypertension, presented with dyspnoea and productive cough of 10 days duration. $\mathrm{He}$ was diagnosed with severe obstructive sleep apnoea 4 years ago, but was non-compliant with continuous positive airway pressure (CPAP) therapy, citing intolerable pressures. He had multiple hospital admissions in the past 6 years, for varying diagnoses, including pneumonia, wheeze and hypercapnic respiratory failure, and was often managed with antibiotic and bronchodilator therapy, oxygen and non-invasive ventilation, but never required invasive mechanical ventilation. He was obese, with tachycardia, tachypnoea, room air saturation of $90 \%$ and bilateral expiratory wheeze on chest auscultation. Blood investigations revealed anaemia. Arterial blood gas showed hypoxaemia. Chest radiograph showed reduced lung volumes with haziness bilaterally. Transthoracic echocardiography showed mild pulmonary hypertension. Blood and sputum cultures were sterile. He was initiated on inhaled bronchodilator therapy, intravenous corticosteroid, continuous noninvasive positive pressure ventilation along with oxygen and subcutaneous insulin. He improved clinically, and was weaned off to nocturnal CPAP therapy. As titrating pressures were subjectively intolerable, he was switched to bilevel positive

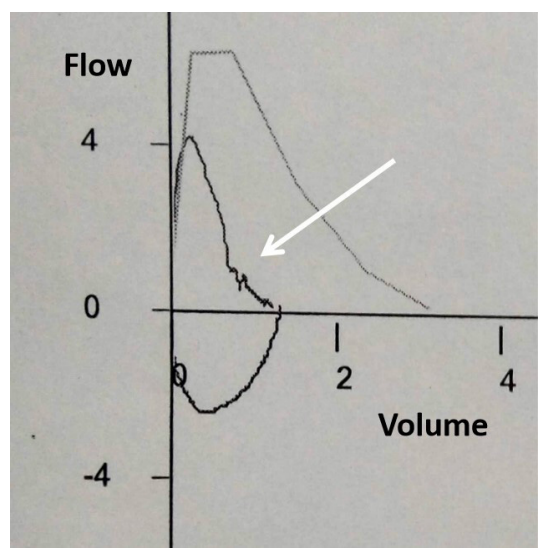

Figure 1 Spirometry showing the flow volume loop with reduced peak expiratory flow, and notching of the expiratory limb (white arrow), with forced expiratory volume in $1 \mathrm{~s}\left(\mathrm{FEV}_{1}\right) /$ forced vital capacity (FVC) of $86 \%$, FVC of $1.28 \mathrm{~L}$ ( $40 \%$ of predicted) and FEV of $1.1 \mathrm{~L}(44 \%$ of predicted), suggestive of restrictive ventilatory defect, possibly secondary to obesity.

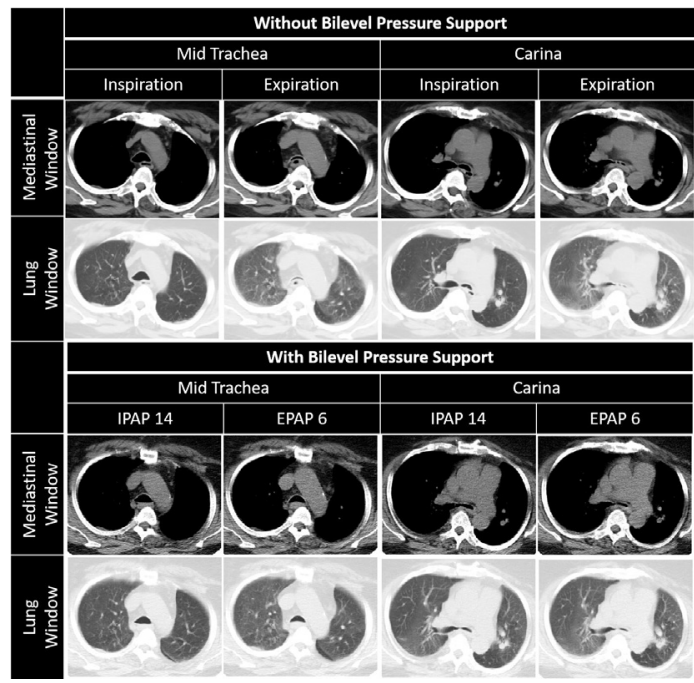

Figure 2 Dynamic CT images of thorax off (top two rows) and on (bottom two rows) bilevel positive airway pressure support (BPAP). Top two rows: when off BPAP, complete collapse of trachea and left main bronchus, and narrowing of right main bronchus, associated with bilateral air trapping (lung window) is seen during expiration. Bottom two rows: with expiratory positive airway pressure (EPAP) of $6 \mathrm{~cm} \mathrm{H}_{2} \mathrm{O}$, the observed luminal patency in trachea and left main bronchus, is less than that which is achieved with an inspiratory positive airway pressure of $14 \mathrm{~cm} \mathrm{H}_{2} \mathrm{O}$ during inspiration. Though the luminal opening of left main bronchus achieved by the lower EPAP is not satisfactory radiologically, it appears sufficient enough and ensures effective ventilation, as shown on dynamic real time imaging, as well as by measured consistent clinical improvement.

airway pressure (BPAP) therapy with inspiratory (IPAP) and expiratory (EPAP) pressures of 14 and $6 \mathrm{cmH}_{2} \mathrm{O}$, respectively. However, when off BPAP, he continued to have wheeze and increased work of breathing. Spirometry showed reduced volumes, with notching of expiratory limb of the flow volume loop (figure 1). A subsequent dynamic non-contrast CT scan of thorax showed expiratory collapse of tracheal and bilateral bronchial lumen, demonstrating tracheobronchomalacia (TBM) and reasonable airway patency achieved with application of BPAP (figure 2). He was discharged and advised to continue BPAP during sleep, and whenever lying supine on bed. A month later, he continued to be compliant on BPAP and remained asymptomatic. 


\section{Patient's perspective}

I was having recurrent hospital admissions for respiratory symptoms over the last 6 years, often requiring intensive care unit (ICU) admission and high pressure mask (NIV). I was told that I was having uncontrolled wheezing which was responsible for frequent admissions. Additionally, I was found to have sleep apnoea 4 years ago after a sleep study test, and I was advised to use a CPAP (continuous positive airway pressure) machine at night during sleep. I found the CPAP pressure intolerable, often leaking from the side of my mask and causing discomfort. I subsequently discontinued CPAP. I continued to use home nebulizer and inhalers, but often with short term relief. During my latest admission 1 month ago, I was told that I had a disease where my airway was closing especially when I am exhaling, which is called tracheobronchomalacia, and this was perhaps the primary problem for my recurrent hospital admissions. I was told that the recommended treatment for this, considering my clinical condition, is also CPAP, which I was reluctant to continue at home. However, in hospital, when the CPAP was switched to another setting with high and low pressures matching my breathing pattern (BPAP, bilevel positive airway pressure), I found this setting more comfortable and acceptable. The doctors subsequently performed a CT scan of my chest off and on this new settings (BPAP) and confirmed that the new settings were adequate to treat my newly diagnosed tracheobronchomalacia as well.

\section{Learning points}

- Tracheobronchomalacia (TBM) is an often forgotten clinical entity, and the diagnosis is often delayed in patients as the symptoms are non-specific. Recurring respiratory symptoms of wheeze, pneumonia, collapse with retained airway secretions and respiratory failure should raise suspicion of this clinical entity. Of the available therapeutic modalities, continuous positive airway pressure (CPAP) appears to be the less invasive and preferred option.

- When patients do not tolerate CPAP for sleep apnoea due to high pressures, CPAP can be switched to bilevel positive airway pressure (BPAP). During BPAP, the lower expiratory positive airway pressure (EPAP) is often well tolerated during expiration.

- However, in coexisting TBM, the lower EPAP in BPAP may be insufficient to ensure airway patency during exhalation. This can however, be confirmed by performing a dynamic CT scan on BPAP.
TBM is defined as excessive expiratory central airway collapse with greater than 50\% luminal narrowing secondary to weakness or instability of the cartilaginous portion of the airway. This occurs secondary to either congenital disease involving connective tissue framework of the airway, or may be acquired, secondary to long standing mechanical or inflammatory airway injury. Symptoms include cough, dyspnoea, wheeze or retained airway secretions, are nonspecific, and often mistaken for other chronic respiratory diseases, leading to a delay in diagnosis. TBM is often confirmed by dynamic chest CT imaging or bronchoscopic examination of the airways during respiration. ${ }^{1}$ Treatment is directed towards keeping the airway patent, achieved by either CPAP, airway stenting or surgical measures such as tracheobronchoplasty or tracheostomy. ${ }^{12}$ Among them, CPAP or BPAP, being a non-invasive intervention, appears to be the preferred approach, especially in elderly patients with multiple comorbidities, and ensures positive airway pressure both during inspiration and expiration. ${ }^{2}$ The latter is essential, as airway collapse in TBM is primarily expiratory. The application of BPAP may not benefit such patients if the lower EPAP applied is less than the opening pressure required to ensure airway patency during expiration. However, real time imaging during application of BPAP, as shown in our patient, can help determine an acceptable EPAP, that although may be insufficient to ensure complete expiratory airway patency, it may be satisfactorily adequate to ensure symptom relief and sufficient ventilation.

Twitter Irfan Ismail Ayub @Irfan_

Contributors NPP and IIA were involved in patient care, drafting and preparation of manuscript, and review of literature. MK was involved in patient care, manuscript revision and review of literature. GP was involved in manuscript revision and review of literature.

Funding The authors have not declared a specific grant for this research from any funding agency in the public, commercial or not-for-profit sectors.

Competing interests None declared.

Patient consent for publication Consent obtained directly from patient(s).

Provenance and peer review Not commissioned; externally peer reviewed.

ORCID iD

Irfan Ismail Ayub http://orcid.org/0000-0001-6109-0044

\section{REFERENCES}

1 Hammond K, Ghori UK, Musani Al. Tracheobronchomalacia and excessive dynamic airway collapse. Clin Chest Med 2018;39:223-8.

2 Bismuth J, Habert P, Boyer A, et al. [Evaluation with chest CT scan of CPAP as a treatment for tracheobronchomalacia in the frame of a Mounier-Kuhn syndrome]. Rev Mal Respir 2020;37:748-51. 
Copyright 2021 BMJ Publishing Group. All rights reserved. For permission to reuse any of this content visit https://www.bmj.com/company/products-services/rights-and-licensing/permissions/

BMJ Case Report Fellows may re-use this article for personal use and teaching without any further permission.

Become a Fellow of BMJ Case Reports today and you can:

- Submit as many cases as you like

- Enjoy fast sympathetic peer review and rapid publication of accepted articles

- Access all the published articles

Re-use any of the published material for personal use and teaching without further permission

Customer Service

If you have any further queries about your subscription, please contact our customer services team on +44 (0) 2071111105 or via email at support@bmj.com.

Visit casereports.bmj.com for more articles like this and to become a Fellow 